\title{
WHAT DOES A STUDENT OF A TEACHING DEGREE LEARN APART FROM SUBJECTS?
}

\author{
Carolina Falcón Linares \\ Department of Education Sciences, University of Saragossa (Spain)
}

\begin{abstract}
Awareness of emotional experiences, vicarious learning and values, in relation to teaching profession, had emerged as a core of interest in previous research. This case study aims to activate awareness of future teachers in several ways. It is about developing critical reasoning about learning from a complexity perspective: (a) training the ability to contextualize learning with their personal beliefs and values, (b) improving strategies to transfer it, and (c) accompanying construction of professional judgment.

The intervention is carried out during two academic years with students of Teaching Degrees in Saragossa (Spain). Learning goals and evaluation are maintained, but teacher-student and peer communication styles are modified. The key to the new methodology is to strengthen the personal and professional narrative in coherence with the subjects. It is a priority that students feel synergies between what they learn, their vicarious knowledge, their emotional memory and the vocation for teaching.

After each semester, discussion groups have been held, obtaining 14 hours of video recording, with the oral narrative data of 215 students divided into groups of 5 . Three emerging categories have been obtained (professional vision, professional development and appreciation of teaching action), and nine subcategories have been defined on a second phase of the analysis.

During university education, there are memorable teachers who motivate action and career leadership, others who go unnoticed, and some who perform a negative influence. The reason is, first, in the unconscious inference of their pedagogical models; and second, in the feelings that have emerged during the time shared with them.
\end{abstract}

Keywords: Preservice teacher education, case study, affective pedagogy, vicarious learning, teacher beliefs.

\section{Introduction}

A great challenge for those who want to be teachers is the familiarity of the work they anticipate to do. Teaching can seem like a natural process, and many people choose teaching because they feel they have an affinity for it or because they consider it a simple profession. The familiar is perceived as attractive and affordable on many occasions. Lortie (1975) explained this pattern as the power of observational learning: the experience that pre-service teachers have had in their lifetime as students. This "learning" confers on them a very solid baggage of vicarious knowledge of which, on the other hand, they are not aware (Shaughnessy and Boerst, 2018). The study by Lortie (1975) underlines the importance of becoming aware of the knowledge and assumptions that students bring to the training process, focusing mainly on practical intuition and beliefs. From the professional experience of the author of this work, it is also necessary to direct conscious reflection towards the values and affective processes that have been linked to vicarious knowledge throughout the academic life (Falcón and Arraiz, 2020).

In a study carried out in the context of training in health sciences, students participate in activities to recognize professional styles based on what they observe in their university professors and in practices tutors. The qualitative description highlights the selective and conscious attention towards the observed roles, better memory strategies and motivation to imitate the observed exemplary models. The powerful impact of awareness of direct and vicarious learnings on professional vision is evident in this research (Horsburgh and Ippolito, 2018).

Regarding teacher training, progress is being made in educational innovation that includes reflective processes on the competencies to be acquired during university training and on the strategies that teachers can implement in this regard (Alsina, Batllori, Falgàs and Vidal, 2019; Domingo and Gómez, 2014; Schrand, Jones and Hanson, 2018; Steenekamp, Van der Merwe and Mehmedova, 2018). 
But there is no solid theoretical framework regarding the communication process that can best activate these processes within university classrooms, despite the fact that the activation of learning from the educational relationship is considered the key factor in performance, above any other didactic strategy (Hattie, 2008). Research is also lacking on the heuristics that students build during their learning regarding teaching models and on how motivation to imitate the best is generated.

The heuristic concept is complex because it involves cognitive, social and emotional construction. But, above all, because it involves learning from experience and the personal elaboration of meanings that include the unconscious imagination. People imagine when they remember and, as well, people use their memory when they imagine. This statement is one of the main conclusions of the study by Conway and Loveday (2015), in which autobiographical memory and the unconscious construction of heuristics emerge as the key factors in the vicarious learning of teaching models.

Research is lacking regarding the processes of awareness about vicarious learning, its integration with training and its transforming power with a professional sense. This case study develops and evaluates a teaching innovation that aims to raise the level of awareness of students during their training process. It is about developing critical reasoning about learning from an upper perspective, applying the three strategies of the analytical-critical method of Schwartz and Sharpe (2010): (a) the ability to contextualize an educational situation and understand it from their beliefs and values, (b) the necessary skills and strategies to make adaptations, and (c) the management of appropriate experiences to make decisions. The objectives are: $1^{\circ}$ ) Foster conscious learning and critical reflection on vicarious experiences with teaching models, in the context of the subject. $2^{\circ}$ ) Know how students live the learning process, how they express themselves about it and what is their assessment of having experienced the subject.

\section{Design and method}

A case study is designed through a teaching innovation program and its qualitative evaluation. The teaching innovation has been developed since 2017 to 2019 with 243 students. Subjects belong to the Degrees of Teacher in Early Childhood Education and in Primary Education, in the first and second year.

Maintaining the usual contents and activities, a communicative model has been adopted focused on the development of narratives by the students. From day one, students have been encouraged to produce individual and group written and oral stories. Strategies for deconstruction of their narratives and critical reconstruction have been worked out from the awareness of new plausible factors of inclusion in their arguments. Imagination games, chained questions and debates have been carried out to activate the recognition of the professional heuristics that they build during the course. The purpose has been to generate conscious learning regarding the contents of the subjects within the framework of their life stories. For example, after performing an activity (case resolution, PBL, visual map, etc.), students analyze it regarding the following variables: direction, sense, value, transfer and integration.

For data collect, students have participated in discussion groups. The topic is the description, interpretation and feeling of the learning process, acquired competences and personal transformation. The activity has been recorded on video outside the classroom, without observation of the teacher or the rest of the group. Videos have been sent to the teacher, as part of the assessment portfolio, which increases their interest and security regarding the privacy of what they relate. Not all students have authorized the use of their videos for research, so about 14 hours of narrative data have been analyzed, corresponding to 215 students.

\section{Results}

Narrative data are analyzed following the Grounded Theory of Bartlett and Payne (1997). After the extraction of significant fragments, they are grouped into conceptual nodes and assigned to different categories. At the end of the analysis, built with NVivo 10, three macro-categories emerge (C1, C2 and C3) which, in turn, include nine subcategories at the second hierarchical level.

Students reflect on their vision of the teaching profession $(\mathrm{C} 1)$ specifying what is the model of a good teacher for them. They explain how they understand different models from their personal history and their feelings. They dialogue and debate about the meaning of the training they are acquiring and how they want to practice in their professional future. This category is divided into: $(\mathrm{C} 1,1)$ Hermeneutical vision of the teaching profession, $(\mathrm{C} 1,2)$ Humanistic vision of the teaching profession and $(\mathrm{C} 1,3)$ Personal identification with a professional model.

The second macro-category is defined as the development of the teaching profession (C2) and shows how they begin to develop their professional identity. They express how some processes help them to be aware of the received influences and to build a career plan. The best rated are the creative openness 
of some activities, practical experiences and simulations, personal tutorials and discussions. This category is divided into: $(\mathrm{C} 2,1)$ Identification of a teacher functions, $(\mathrm{C} 2,2)$ Awareness about professional identity and $(\mathrm{C} 2,3)$ Integration of knowledge from critical reflection.

Third, the assessment of teaching action (C3) is defined, which includes very diverse contributions on the reflective method based on awareness. The work of linking theory, practice and previous experiences is recognized. And it is appreciated that dynamic and participatory communication processes have motivated learning and deepening outside the classroom. The three subcategories are: $(\mathrm{C} 3,1)$ Positive: experiential and memorable formative experience, $(\mathrm{C} 3,2)$ Negative: resistance to change and uncertainty about the assessment and $(\mathrm{C} 3,3)$ Satisfaction and motivation focused on new challenges.

\section{Conclusions}

Implicit learning about the profession, with which students enter the Faculties of Education, conditions any future reflective intervention and their own professional identity. It is the baseline on which to start projecting the necessary skills to be good teachers, overcoming the fallacy of believing that they begin teachers training when they come to the Degree. Guided reflection on teaching models has made it possible to integrate past, present and future in the learning process of the subjects (Shaughnessy and Boerst, 2018). That is, students have acquired a professional vision of their vicarious learning, becoming aware of how past and present experiences are integrated with new knowledge and serve to design the future career project.

Teaching role has been the main object of reflection and change regarding communication, attitude in class and in tutoring. Sensitive and vocational learning has been enhanced, adopting horizontal democratic relationships with students. The most valued of the communicative model implemented is the way to stimulate authentic and personalized participation, activating student learning, instead of just facilitating it (Hattie, 2008). But it is unknown what long-term effects the intervention aimed at causing the conscious emergence of vicarious knowledge, beliefs, emotional experiences and values may have. The next phase consists of expanding the design to a study with a larger sample, which also includes longitudinal and quantitative data.

\section{References}

Alsina, Á., Batllori, R., Falgàs, M. y Vidal, I. (2019). Marcas de autorregulación para la construcción del perfil docente durante la formación inicial de maestros. Revista Complutense de Educación, 30(1), 55-74.

Bartlett, D. \& Payne, S. (1997). Grounded theory. Its basis rationale and procedures. In: McKenzie, G., Powell, J. \& Usher, R. (eds). Understanding Social Research: Perspectives on Methodology and Practice (173-195), London: Falmer Press.

Conway, M.A. \& Loveday, C. (2015). Remembering, imagining, false memories and personal meanings. Consciousness and Cognition, 33, 574-581.

Domingo, A. y Gómez, M.V. (2014). La práctica reflexiva. Bases, modelos e instrumentos. Madrid: Narcea.

Falcón-Linares, C. y Arraiz, A. (2020). Construcción de la identidad profesional docente durante la formación inicial como maestros. Revista Complutense de Educación, 31 (3), 329-340.

Hattie, J. (2008). Visible Learning: a synthesis of over 800 meta-analyses in education. London: Routledge.

Horsburgh, J. \& Ippolito, K. (2018). A skill to be worked at: using social learning theory to explore the process of learning from role models in clinical settings. BMC Med Educ, 18, 156.

Lortie, D. (1975). Schoolteacher: A sociological study. Chicago, IL: University of Chicago Press.

Schrand, T., Jones, K. \& Hanson, V. (2018). "Reflecting on Reflections": Curating ePortfolios for Integrative Learning and Identity Development in a General Education Senior Capstone. International Journal of ePortfolio, 8(1), 1-12.

Schwartz, B. \& Sharpe, K. (2010). Practical wisdom: The right way to do the right thing. New York, NY: Riverhead Books.

Shaughnessy, M. \& Boerst, T.A. (2018) Uncovering the Skills That Preservice Teachers Bring to Teacher Education: The Practice of Eliciting a Student's Thinking. Journal of teacher education, 69(1), 40-55.

Steenekamp, K., Van der Merwe, M. y Mehmedova, A.S. (2018). Enabling the development of student teacher professional identity through vicarious learning during an educational excursion. South African Journal of Education, 38(1). 